\title{
Great saphenous vein remodeling using LASER with low-energy linear endovenous energy density, no tumescence, and associated surgical techniques
}

\author{
Ferracani $\mathbf{E}^{1^{*}}$, Bercovich $\mathbf{J}^{2}$ and Schulte $\mathbf{C}^{3}$
}

Ferracani E, Bercovich J, Schulte C. Great saphenous vein remodeling using LASER with low-energy linear endovenous energy density, no tumescence, and associated surgical techniques. J Phlebol Lymphol. 2018;11(1):28-33.

The objective was reduce at the half the GSV diameter trough remodeling of the great saphenous vein by 1470 LASER LEED flexibility (setting parameters) as a method to counteract Valsalva reflux.

A prospective study of 38 patients done in two centers is presented using a combined approach of sparing techniques plus LASER $1470 \mathrm{~nm}$.The purpose was avoid unnecessary ablation of the great saphenous vein (GSV) at the early hemodynamic stages (diameter below $9 \mathrm{~mm}$, peak

\section{INTRODUCTION}

The objective of this work is to remodel the saphenous vein by the capacity of the 1470 LASER to reduce the parietal collagen of the Magna saphenous vein associating current preservation techniques, in early hemodynamic stages avoiding systematic ablation based currently only in reflux time.

A key stone of this pioneering strategy is measuring the total volume of reflux that depends mostly in the vein Area and not just the reflux time as parameter of ablation.

There are no articles in the literature of this strategy that combine the properties of 1470 LASER at low LEED plus conservative techniques, being a pioneering work in phlebology research.

The first attempt began done under this hypothesis, was try to reduce the dilated saphenofemoral junction with an internal laser valvuloplasty below the valve leaflets.

This work was published by the Argentine Society of Phlebology in 2013 [1] (Flebologia SAFYL) and a modification was published in a short article in 2013 [2] and then commented by Gianesini MD [3].

The actual concept is that vein lesser than $5 \mathrm{~mm}$ (small diameter) does not reach enough volume $30 \mathrm{cc} / \mathrm{sec}$, necessary to affect the muscle pump performance [4].

The first attempt for vein sparing plus valvuloplasty was done using radiofrequency but results showed an unacceptable number of thrombosis of the GSV [5].

Using concepts of physics such as, Pouiselle law, Laplace law, Bernouili equation, and the potential energy is counteracted and diminished by reducing the impact that affects the SF junction and valves (shear stress).

Most are these principles are used in sparing techniques [6-10]. The investigation added Laser 1470 collagen shrinkage properties to reduce the diameter of the vein. reflux speed below $30 \mathrm{cc} / \mathrm{s}$ and total reflux volume (TRV) between 10 and $100 \mathrm{cc} / \mathrm{s}$ )

The study was under the supervision of the Ethical Committee and Scientific Department of the Argentine Society of Phlebology and Lymphology, Chairman Dr. Daniel Garcia, June 9 2017, and approved during the plenary session. No number registration was given. Each patient gave signed informed consent. Thirty-eight middle-aged patients, 29 women and 9 men, with clinical, etiologic, anatomic, pathophysiologic (CEAP) classification $\mathrm{C} 2-5$ were included.

This study does not record background into the world bibliography, therefore doesn't exist comparison parameters available.

Key Words: GSV ablation, LASER valvuloplasty, Vascular.

The target of 1470 LASER is water and collagen reacts shrinking and reducing the vein diameter.

The reduction of dilated vein at normal diameters acts as a normal resistance accordingly with the Laplace formula: Flow is directly proportional at pressure (Valsalva into the venous system) and inversely proportional to the resistance (restored diameters).

There are two theories about the origin of the vein disease.

Only $49 \%$ of the great saphenous veins (GSV) superficial venous insufficiencies are due to insufficiency of the femoral saphenous vein after the effects of shear stress, activation of leucocytes and valve damage. The treatment will depends about what frame of the venous disease story we are watching, the $4 \mathrm{~mm}$ diameter with Reflux measured in seconds or the $10 \mathrm{~mm}$ diameter, a Peak Reflux Volume greater than $100 \mathrm{cc}$.

The remainder are of extra-ostia origin and do not justify ablations of the GSV $[11,12]$. The first was a gravitational descending explanation. The last one is an inflammatory disease due to MMP and cytokines released at the fifth microvascular level $[13,14]$.

The increase in shear stress over the vascular wall [15-18] is the most important cause of parietal factor vein damage.

This triggers the valve damage mediated by cytokines and initiates the descending phase of the great saphenous vein dilation and the last frames of the movie called superficial venous insufficiency.

The ideal treatment of the initial venous disease should be avoid the valvar damage (19), counteract the inflammatory cascade counteracting each physical and chemical factor by reducing the Total Reflux Volume.

Resection of insufficient tributaries reduces pressure and volume inside the vein, diameter return to normal as shown the ASVAL method.

Laplace law is the flow equation and explains that flow is directly proportional of pressure and indirectly to diameter .Here the diameter (Resistance) $\mathrm{F}=\mathrm{P} / \mathrm{R}$ is almost zero.

${ }^{1}$ Navy Hospital Dr Pedro Mallo, Instituto Privado De Flebologia Y Laser Ecoguiado Caba, Argentina

${ }^{2}$ Bazterrica Clinic, Venous Surgery Department, Buenos Aires, Argentina

${ }^{3}$ Los Arcos, Clinic Ultrasound Department, Buenos Aires, Argentina

*Correspondence: Enrique Luis Ferracani, Navy Hospital Dr Pedro Mallo, Instituto Privado De Flebologia Y Laser Ecoguiado' Caba, Argentina, Email:eferracani@gmail.com; Doi: 10.14303/1983-8905.1000055

Received: April 24, 2018, Accepted: May 21, 2018, Published: May 28, 2018

OPEN $\bigcirc$ ACCESS

J Phlebol Lymphol Vol.11 No.12018
This open-access article is distributed under the terms of the Creative Commons Attribution Non-Commercial License (CC BY-NC) (http:// creativecommons.org/licenses/by-nc/4.0/), which permits reuse, distribution and reproduction of the article, provided that the original work is properly cited and the reuse is restricted to noncommercial purposes. For commercial reuse, contact reprints@pulsus.com 
The remodeling at normal diameter by normalizing the diameter acts as a resistance counteracting the pressure of Valsalva.

Remodeling obviously requires a non-occlusive vein diameter reduction. Consumption of the Valsalva front line pressure [20]. The diameter reduction of GSV travers area and the consequence of theses action are reduction of distal reflux flow.

The previously mentioned resection of insufficient tributaries, according to the Bernoulli equation (energy=pressure $x$ volume) is the basis of ASVAL method. The result is a shear stress reduction, has its effect on the saphenous wall (Figure 1).

The SFJ is only reduced in diameter at $5 \mathrm{~cm}$ below the junction, (no crosectomy is formal).

Preservation of all the reentering perforators and close all reflux points is mandatory.

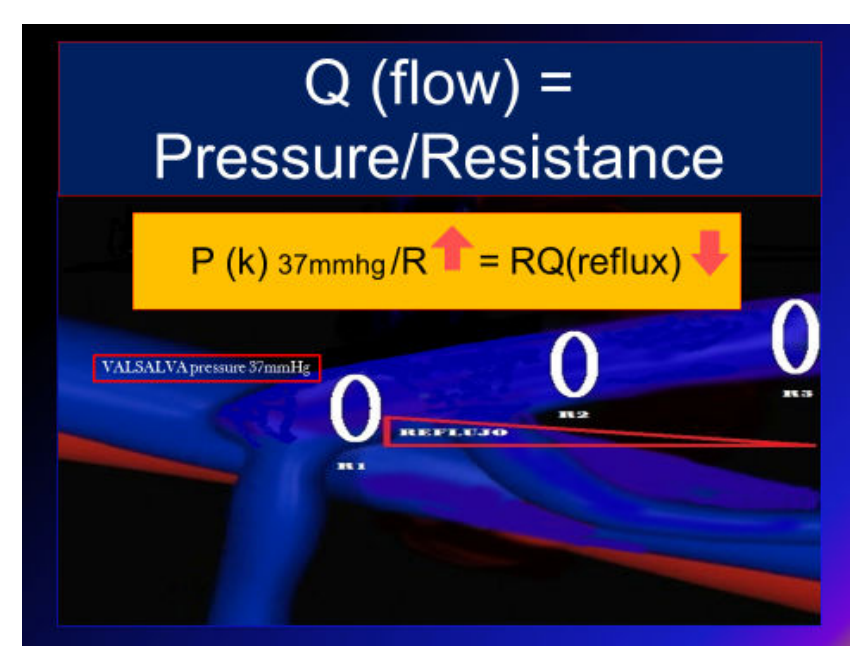

Figure 1: Scheme of the flow formula.

At a constant pressure front line, if the resistance increases by reducing the dilated vein segments, the pressure front line is consumed and the reflux decreases distally.

\section{MATERIALS AND METHODS}

The research was divided into two phases.

Phase I was to try and reproduce collagen LASER shrinkage. This was done in a patient with GSV recurrence.

Phase II was to try to reduce the GSV area and compare the preoperative reflux lower post op pressure obtained. The protocol required an independent ultrasound (US) study measuring diameter, area, peak of reflux, and average peak, cc/seconds.

Then the surgeon checks the results and performed preoperative mapping and measurement of the venous area to be treated. This evaluation was performed twice, in supine decubitus for under controlled Valsalva (40 $\mathrm{mmHg}$ ).

All results were tabulated into three stages based on ultrasound results obtained (Figure 2).

The Hemodynamic Consensus [21] where area is accepted the main cause of reflux was a key piece for the remodeling idea for total reflux reduction.

Prof. Takashi Yamaki's concepts were used as a mayor index, the quantitative reflux; total volume reflux TRV as future severity index [22-24]. The formula that enables the measurement total reflux volume is the following:

$\mathrm{TRV}=$ Mean reflux velocity $\times$ AREA $\left(\mathrm{r}^{2}\right) \times$ Time
Phase II demonstrated the relationship between area and total reflux volume (TRV) as quantitative indexes of reflux evaluation. Time of reflux is just qualitative, not quantitative and not representative of venous disease severity.

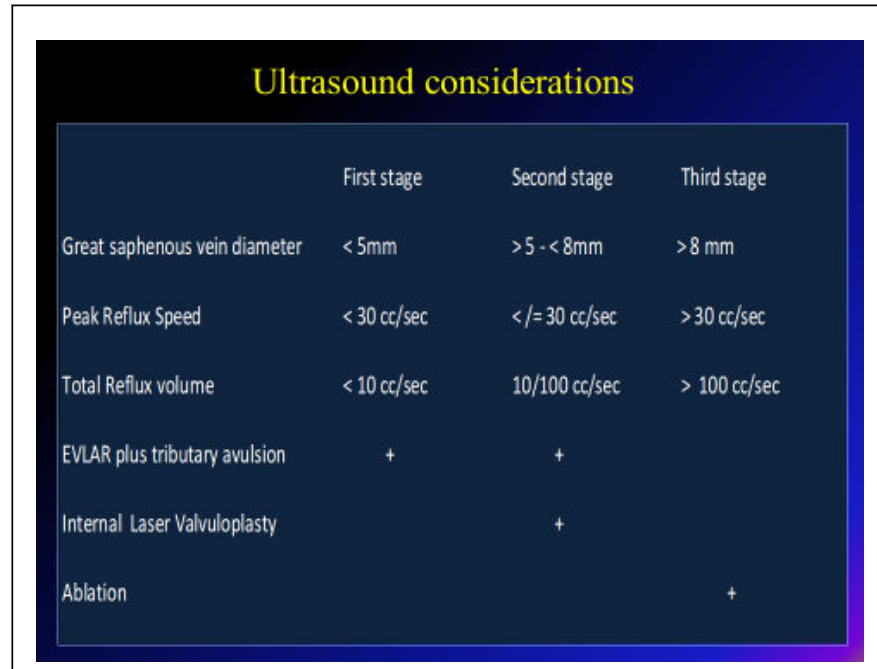

Figure 2: Ultrasound considerations.

The second stage is the best option for venous remodeling.

\section{Surgical considerations}

The procedure is done in a clinic because it is not allowed do any surgery in Argentina in an office based environment; sedation and local anesthesia at the puncture site are used and LASER shooting areas The low LEED used makes the procedure painless.

Tumescent technique is not used for improve ultrasound images. The Area is watched before and after each shoot.

A minislim fiber was introduced trough an infrapatellar Seldinger puncture under US control. The methodology doesn't require the remodeling of the entire vein.

There are two options for remodeling setting:

- fixed: if the vein is dilated in a large longitudinal segment, (not common in phase two hemodynamically considerations), area remodeling reduction is done at $5,10,15,20$ and $25 \mathrm{~cm}$ below of the (SFJ); and

- flexible: only the vein dilated segments are treated. The fiber tip is positioned at the center of the vein. A pulse mode of 4 watts lasting 6 seconds LEED $(24 \mathrm{~J} / \mathrm{cm})$ is used in one shot. The ultrasound area is measured after each laser shot, and a white ring (collagen shrinkage) will appear. Repeat the shoot if necessary with a two-fold recovery time. Decreasing the radius by a factor of 2 , decreases the flow by a factor of 16; this reduction in the vein's diameter increases the resistance to the Valsalva pressure, counteracting the reflux front line according to the Pouiselle equation. After each shot, if the area reduction is the desired one, the next point should be treated. The surgeon can repeat the shot, but only three times for each segment. The extension of LASER shrinkage is less than $2 \mathrm{~cm}$ during a slow pullback and the extension of the longitudinal dilatation should be taken into consideration.

The method only uses the preservation of reentry points, closing of all reflux points and never performed a crosectomy.

This open SFJ allows physiologic systolic return and, during muscle diastole, in reverse direction looking for the re-entry perforator as CHIVA 1 does.

Once the remodeling is completed, stab avulsion of insufficient tributaries is performed with Muller ASVAL technique. The purpose is to decrease 
the shear stress (counteract Bernouilli equation; Energy=Pressure $\times$ Volume).

US control of the treated vein is a good practice in order to measure the reflux under Valsalva and end the procedure. An elastic bandage should be applied, and early ambulation and US control the day after the procedure, is recommended. Protection with low heparin subcutaneously (3500 IU) was given in all patients for three days.

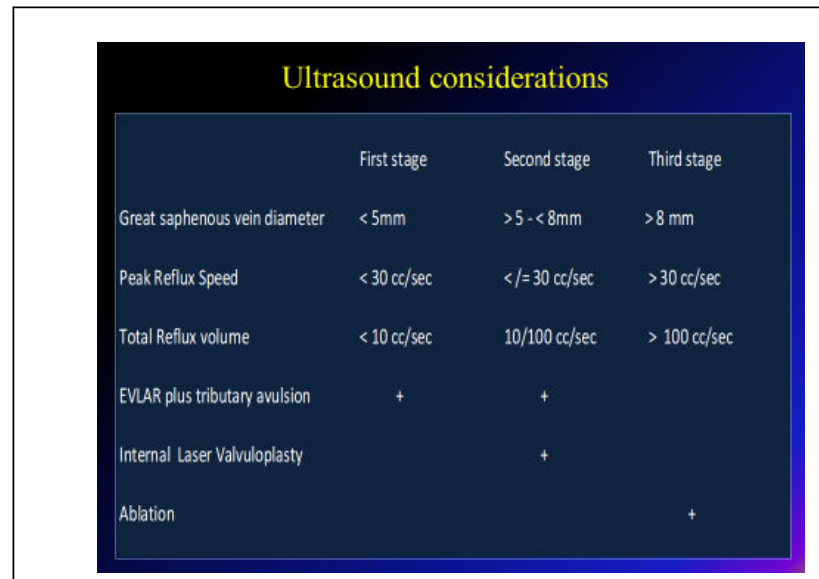

Figure 3: Technical diagram.

\section{RESULTS}

Consulted bibliography concerning a similar procedure is not existent and this could be considered a pioneer work as a strategy based on physics, sparing methods and 1470 LASER as an instrument.

\begin{tabular}{|c|c|c|c|c|}
\hline Area $\mathrm{cm}^{2}$ & & VTR CC/Segundos & & \\
\hline Area Pre & Area Post & Vtr Pre & Vtr Post & \\
\hline 0,12 & 0,06 & PREVAIT & $\begin{array}{l}\text { no } \\
\text { measurement }\end{array}$ & -reflux \\
\hline 0,65 & 0,25 & 34,13 & 5,63 & \\
\hline 1,51 & 0,4 & 207,6 & 17,5 & \\
\hline 0,94 & 0,11 & 52 & 0,63 & \\
\hline 0,52 & 0,32 & 46,8 & 2 & \\
\hline 0,58 & 0,25 & 17,85 & 3,6 & \\
\hline 0,33 & 0,15 & 8,48 & 0,9 & \\
\hline 0,43 & 0,37 & 41,64 & 12,51 & \\
\hline 0,4 & 0,32 & occlusion at $1 \mathrm{st}$ month & & \\
\hline 0,34 & 0,15 & 18,96 & 5,18 & \\
\hline 0,16 & 0,09 & 9,89 & 0,41 & \\
\hline 0,5 & 0,12 & 42,33 & 2,26 & \\
\hline 0,39 & 0,15 & 61,08 & 6,12 & \\
\hline 1,17 & 0,88 & 81,45 & 44 & \\
\hline 0,71 & 0,14 & 83,66 & 0,62 & \\
\hline 0,9 & 0,28 & 36,31 & 0 & \\
\hline 0,89 & 0,25 & 39,3 & 5,59 & \\
\hline 0,68 & 0,2 & 72 & 0,63 & \\
\hline 0,18 & 0,12 & 273 & 18,8 & \\
\hline
\end{tabular}

\begin{tabular}{|c|c|c|c|}
\hline 0,159 & 0,11 & 946 & 9,3 \\
\hline 0,4 & 0,19 & 2720 & 19 \\
\hline 0,17 & 0,13 & 269,2 & 13 \\
\hline 0,57 & 0,4 & 169,5 & 20,8 \\
\hline 0,76 & 0,13 & 2131,8 & 64,4 \\
\hline 0,198 & 0,13 & 1255 & 13,2 \\
\hline 0,31 & 0,14 & 1581 & 39,2 \\
\hline 0,12 & 0,08 & 1111,25 & 8,6 \\
\hline 0,15 & 0,093 & 400,6 & 7,81 \\
\hline 0,16 & 0,09 & 187,45 & 9 \\
\hline 0,17 & 0,11 & 310 & 11 \\
\hline 0,36 & 0,13 & 806,4 & 17,9 \\
\hline 0,39 & 0,22 & 1170 & 22 \\
\hline 0,3 & 0,1 & 621 & 14 \\
\hline 0,53 & 0,2 & 5843 & 20 \\
\hline 0,9 & 0,4 & 348 & 24 \\
\hline 0,98 & 0,5 & 264 & 5 \\
\hline 0,35 & 0,18 & 320 & 18 \\
\hline 0,23 & & $\begin{array}{l}\text { spasm } \\
\text { intraoperatrory }\end{array}$ & oclussion \\
\hline 18,37 & 7,94 & 21632 & 463 \\
\hline
\end{tabular}

Table 1: To study the effect on the vein wall of the low LEED.

Area and TRV showed a statistically significant reduction. The difference in areas, pre-EVLAR procedure and post-procedure, showed a median of -0.2 , with a $p$-value of $<0.0001$. The difference for the TRV pre and post EVLAR procedure showed a median difference value of -190.1, $\mathrm{p}<0.0001$. All patients were asymptomatic in CEAP class $\mathrm{C} 1$. The obtained results were an area reduction of $43,2 \%$ and a reflux reduction of $97.9 \%$ with GSV open.

To study the effect on the vein wall of the low LEED, a treated vein with laser sample was obtained, previous patient signed consent, $(4 \mathrm{~mm}$ anterior accessory vein) during an open procedure to check the histological results. A sample was submitted to the Anatomopathology Department, at the University of Medicine, Buenos Aires, Argentina. No endothelial injury was observed; the media showed vacuolization of collagen, and no thrombosis or adventitial damage.

Four occlusions of the saphenous vein after 2 weeks of follow-up were registered. Two patients showed spontaneous recanalization during follow-up and no reflux ( 2 pts. $-5 \%$ ). Two definite saphenous occlusions without posterior recanalization were recorded. the first a 32 year old female that had a preoperative GSV diameter of $7.5 \mathrm{~mm}$ determined by US , during the procedure diameter reduces spontaneously to $3 \mathrm{~mm}$. In young female the collagen is more reactive and could be a possible explanation of vein spasms [25].The second failure was the use of a radial fiber, thicker than the radial minislim.

LEED below $24 \mathrm{~J} / \mathrm{cm}$ does not usually damage the endothelium. The middle layer is vacuolated and collagen fiber redirection and shrinkage is observed in the histological study. Three-layer parietal damage is achieved only with LEED $>75 \mathrm{~J} / \mathrm{cm}$ [26]. On the other hand, the endothelium has the power to self-repair itself. For instance, re-endotelization post-arterial angioplasty repairs the endothelium after 5 months [27]. Non-intra or postoperative complications with this strategy were registered. 


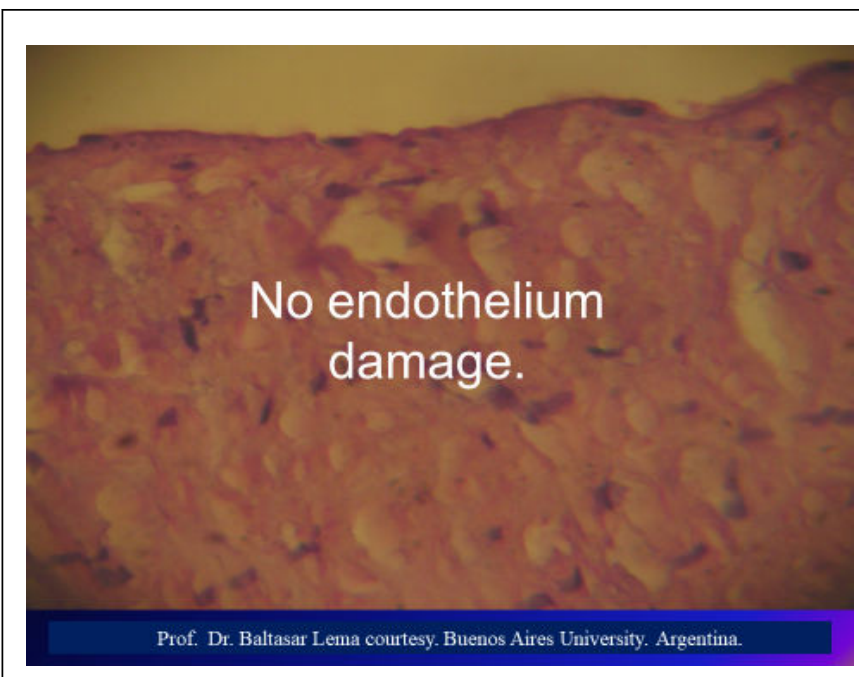

Figure 4: Anathomopathological in vivo study of the anterior accessory vein, with patient consent and of the ethical committee, was done before ablation of an insufficient Accessory anterior vein and before remodeling of the GSV. The endothelium can be seen without damage or adventitial damage.

Application scenarios of this strategy for anatomical preservation (sparing concept) could be : (i) reflux of the saphenous vein with continent femoral valve (ideal saphenous veins diameters to apply this strategy are veins greater than $5 \mathrm{~mm}$ and less to $9 \mathrm{~mm}$ ); (ii) patients with insufficiency triggered by tributaries and secondary dysfunction of the terminal, preterminal or saphenous-ostial valves; (iii) segmental venous dilatation; (iv) young patients and patients with arteriosclerotic risk factors or juvenile diabetics.

Saphenous ducts preservation, even with reflux below $30 \mathrm{cc} / \mathrm{sec}$; for future revascularization surgery of lower limbs, critical ischemia must be emphasized.

Nowadays anatomical capital sparing concept is getting stronger access into the community of vascular specialist, avoiding destruction of small diameter vessels, especially in young people and with smaller veins.

Three years of follow-up was achieved in $50 \%$ of patients. The US control revealed open veins, reduction in reflux and preserved upstream flow during systole and inversed flow through the re-entry perforator during diastole. The follow up showed evolution of the disease; one patient with common Femoral Vein insufficiency not present at the beginning of investigation, may be due to overweight and sedentarism and two insufficient hunter perforator.

\section{DISCUSSION}

This procedure could be another option of superficial venous disease treatment to prevent further damage and irreversible dilatation of the saphenous vein at early hemodynamic stages with peak reflux below 30 $\mathrm{cc} / \mathrm{sec}$ and GSV diameter below $9 \mathrm{~mm}$. One theory explains that the origin of the GSV insufficiency initiates at the distal level by the release of MMP by extra fascial tributaries of the fifth order. The origin of venous disease is reported as a non-infectious inflammatory response due to leukocyte activation [28]. These cause endothelial and valvar damage. The valvar damage generates a feedback circuit by reflux during Valsalva pressure, recruiting then normal tributaries and closing the circle. Ablation in the treatment of venous disease is indicated only with reflux greater than 30 $\mathrm{cc} / \mathrm{sec}$ (peak value) and never in veins lesser than $6 \mathrm{~mm}$. Pittaluga and Chastanet experience, showed that only the resection of tributaries led to the decrease of the GSV diameter and reflux reduction [29]. Zamboni and Cappelli [30] demonstrated that the insufficient reflux annulment would allow the preservation of the GSV without sapheno-femoral disconnection based on the RET maneuver (reflux elimination test with duplex ultrasound).

After the surgical ablation, hemodynamic conditions return to normal status; however, a short time later, as the conditions of deep systolic calf hypertension remain present, a recurrence of varicose veins is the final result, which is called "paradoxical phenomena" [31]

In addition, the Cochrane database study [32,33] showed that varicose veins recurrence with non-ablative methods is lower than ablative methods with a risk ratio of $0.63 \%$ versus $0.78 \%$.

It drew our attention and we paid great attention of data of LASER recanalization without reflux and asymptomatic patients, from the analysis of international records like the IRWIG study [34] and from a metaanalysis [35]. The initial results of the endovascular laser showed a $4 \%$ saphenous vein recanalization rate. The analysis of this and other works revealed that recanalization existed in asymptomatic patients with no reflux $(11.9 \%)$ [36].

The explanation for this supposed "failure" lies in the contraction (shrinking) of the collagen, the restoration of the dilated saphenous diameters creating a resistance of reflux and the abolition of insufficient tributaries. The reduction of the area of the GSV generates a resistance to the pressure front line and reduction of reflux distally.

Over many years, the saphenous vein was considered to be a conduit for arterial bypass but with poor patency rates. The poor patency rates were based on the destruction of vein vasa vasorum.

Nowadays, the non-touch saphenous vein technique have shown greater patency rates than the radial artery after 3 years of bypass, similar to internal thoracic artery (ITA), and it is currently used in critical limb ischemia [37-42].

Today, mechanical and chemical occlusive methods are indicated in most cases around the world without evaluating anything more than the reflux time.

Finally, the UIP Hemodynamic Consensus made by Dr LEE et al. (Rome 2016) sheds light on the prevailing hemodynamic darkness.

\section{CONCLUSIONS}

The exposed technique, being a conservative strategy, showed a progressive reduction of diameters and reflux volume, an asymptomatic patient, and stability at 4 years of follow-up. The reflux drops intraoperatively, stabilizes at 3 months between values ranging from 0.5 to $1 \mathrm{cc} / \mathrm{sec}$. The curve recorded is a reverse flow looking for a diastole reentrant perforator.

Not doing crossectomy avoids paradoxical phenomenon and guarantees a doubly drained system; both systolic and diastolic. The unnecessary ablation of sufficient tributaries, during classic crosectomy, avoids poorly drained ducts.

This endovascular LASER strategy supported by hemodynamic principles as Bernoulli equation, endovascular hydrodynamic, endovenous and perivenous pressure, flow formula, shear stress concept, is very easy to implement for all vascular surgeons.

Currently, the GSV has recovered its importance as a bypass conduit. For that reason, the patient must be warned about its preservation, as long as possible, of his/her anatomical capital. This modest initial experience must be corroborated and experienced by other researchers, greater number of patients and further publications.

\section{ACKNOWLEDGMENTS}

Our gratitude to Maronna $\mathrm{PhD}$ for their assistance in statistical analysis; to Passariello $\mathrm{F} \mathrm{PhD}$, Yamaki $\mathrm{T} \mathrm{PhD}$ and Spreafico $\mathrm{G} \mathrm{PhD}$ for the suggestions to write this paper. Finally my appreciation to argentine pioneers in valve repair Enrici $\mathrm{H} \mathrm{PhD}$, Simkin $\mathrm{R} \mathrm{PhD}$ and Onoratti $\mathrm{D} \mathrm{PhD}$ [43-45]. 


\section{CONFLICTS OF INTEREST}

No potential conflict of interest is reported.

\section{REFERENCES}

1. Ferracani E. Internal laser valvuloplasty and venous remodeling using 1470laser. Initial experience. Flebologia. Sociedad Argentina de flebologia y linfologia. 2013;3:39-40.

2. Ferracani E. Saphenous sparing laser modern options. Veins Lymphat. 2013;2:e21.

3. Gianesini S. Reply to: Saphenous sparing laser modern options. Veins Lymphat. 2013; 2:e21.

4. Raju S, Ward M, Jones TL. Quantifying saphenous reflux. J Vasc Surg Venous Lymphat Disord. 2015;3:8-17.

5. Danielsson G, Jungbeck C, Peterson K, et al. Venous function after restoring valve competence of the great saphenous vein. J Endovasc Ther. 2003;10:350-355.

6. Franceschi C, Cappelli M, Ermini S, et al. CHIVA: hemodynamic concept, strategy and results. Int Angiol. 2016;35:8-30.

7. Franceschi C. Théorie et pratique de la cure conservatrice et hémodynamique de l'insuffisance veineuse en ambulatoire. Precysous-Thil: Editions de l'Armançon 1988.

8. Franceschi C. Dynamic fractionizing of hydrostatic pressure, closed and open shunts, vicarious varicose evolution: how these concepts made the treatment of varices evolve? Phlebologie. 2003;56:61.

9. Franceschi C. La cure hemodynamique de l'insuffisance veineuse en ambulatoire. J Mal Vasc. 1992;17:291-300.

10. Zamboni P, Escribano JM. Regarding 'Reflux elimination without any ablation or disconnection of the saphenous vein. A haemodynamic model for venous surgery' and 'Durability of refluxelimination by a minimal invasive CHIVA procedure on patients with varicose veins. A 3-year prospective case study'. Eur J Vasc Endovasc Surg. 2004;28:567.

11. Navarro TP, Nunes TA, Ribeiro AL, et al. Is total abolishment of great saphenous reflux in the invasive treatment of superficial chronic venous insufficiency always necessary? Int Angiol. 2009;28:4-11

12. Cappelli M, Lova MR, Ermini S, et al. Hemodynamics of the sapheno-femoral complex: an operational diagnosis of proximal femoral valve function. Int Angiol. 2006;25:356-360.

13. Vincent JR, Jones GR, Hill GB, et al. Failure of micro venous valves in small superficial veins is a key to the skin changes of venous insufficiency. J Vasc Surg. 2011;54:62S-69S.

14. Chang JW, Maeng YH, Kim SW. Expression of Matrix Metalloproteinase-2 and 13 and Tissue Inhibitor of Metalloproteinase-4 in Varicose Veins Korean J Thorac Cardiovasc Surg. 2011;44:387-391.

15. Labropoulos N, Giannoukas AD, Delis K, et al. Where does venous reflux start? J Vasc Surg. 1997;26:736-742.

16. Schönbein WS. Triggering mechanisms of venous valve incompetence. The Venous Valve and Primary Chronic Venous Disease. Medicographia. 2008;30:121-126.

17. Coleridge-Smith P, Labropoulos N, Partsch H. Duplex ultrasound investigation of the veins in chronic venous disease of the lower limbs-UIP consensus document. Part I. Basic principles. Eur J Vasc Endovasc Surg. 2006;31:83-92.

18. Labropoulos N, Kang SS, Mansour MA, et al. Primary superficial vein reflux with competent saphenous trunk. Eur J Vasc Endovasc Surg. 1999;18:201-206.

19. Jawien TA. Treatment of venous valve incompetence: past, current, and future. The Venous Valve and Primary Chronic Venous Disease. Medicographia. 2008;30:131-136.

20. Bar-Meir G. Basics of fluid mechanics (version 0.3.1.1) 2011.

21. Lee MD et al. UIP Hemodynamic Consensus. Int Angiol. 2016;35:262-265
22. Yamaki T. Comparing duplex ultrasound scanning between the US and abroad department of plastic and reconstructive surgery Tokyo women's medical university. ACP Annual Congress Presentations. 2011.

23. Yamaki T, Nozaki M, Sakurai H, et al. High peak reflux velocity is a strong predictor of advanced post-thrombotic sequelae. J Thromb Haemost. 2007;5:305-312.

24. Yamaki T, Nozaki M, Sakurai K, et al. Advanced chronic insufficiency is associated with increased calf muscle deoxygenation. Eur J Vasc Endovasc Surg. 2010;39:787-794.

25. Cross KS, Davies MG, El-Sanadiki MN, et al. Long-term human vein graft contractility and morphology: a functional and histopathological study of retrieved coronary vein grafts. Br J Surg. 1994;81:699-705.

26. Parikov M. Vol 32 Suppl.1Nro 5 pag. 159. XVII UIP BOSTON 2013.

27. Martínez-Gonzáleza J, Badimona L. Reendotelización, engrosamiento intimal y remodelado vascular. Un denominador común? Rev Esp Cardiol. 2000;53:1425-1427.

28. Schonbein GW. Triggering mechanism of venous valve incompetence. The Venous Valve and Primary chronic venous disease. Medicografia. 2008;30:121-126.

29. Pittaluga P, Chastanet S, Bernard R, et al. Preservation of The Saphenous Vein in Patients with Varicose Veins. IMP Vascular. 2005;6:182-189.

30. Zamboni P, Cisno C, Marchetti F, et al. Reflux eliminationwithout any ablation or disconnection of the saphenous vein. A haemodynamic model for venous surgery. Eur J Vasc Endovasc Surg. 2001;21:361-369.

31. Recek C. The hemodynamic paradox as a trigger phenomenon of recurrent venous reflux disease with varicose veins. Int J Angiol. 2012;21:181-186.

32. Bellmunt-Montoya S, Escribano JM, Dilme J, et al. CHIVA method for the treatment of chronic venous insufficiency. Cochrane Database Syst Rev. CD009648 2013.

33. Bellmunt-Montoya S, Escribano JM, Dilme J, et al. CHIVA method for the treatment of chronic venous insufficiency. Cochrane Database Syst Rev. 2015.

34. International Endovenous Laser Working Group, Spreafico G; Kabnick L; Berland TL; Cayne NS; Maldonado TS; Jacobowitz GS; Rockman CR; Lamparello PJ; Baccaglini U; Rudarakanchana N; Adelman MA Centro Multidisciplinare Day Surgery, Azienda Ospedaliera-Università,Padova, Italy.

35. van den Bos R, Arends L, Kockaert M, et al. Endovenous therapies of lower extremity varicosities: A meta-analysis. J Vasc Surg. 2009;49:230-239.

36. Pannier F, Rabe E. Mid-term results following endovenous laser ablation (EVLA) of saphenous veins with a $980 \mathrm{~nm}$ diode laser. Int Angiol. 2008;27:475-481.

37. Dreifalt M, Mannion JD, Bodin L, et al. The no Touch saphenous vein as the preferred second conduit for coronary artery bypass grafting. Ann Thorac Surg. 2013;96:105-111.

38. Samano N, Geijer H, Liden M, et al. The no-touch saphenous vein for coronary artery bypass grafting maintains a patency, after 16 years, comparable to the left internal thoracic artery: A randomized trial. J Thorac Cardiovasc Surg. 2015;150:880-888.

39. Romiti M, Albers M, Brochado-Neto FC, et al. Meta-analysis of infrapopliteal angioplasty for chronic critical limb ischemia. J Vasc Surg. 2008;47:975-981

40. Albers M, Romiti M, Brochado-Neto FC, et al. Meta-analysis of popliteal-to-distal vein bypass grafts for critical ischemia. J Vasc Surg. 2006;43:498-503.

41. Ziza V, Canaud L, Gandet T, et al. Outcomes of cold-stored venous allograft for below-knee bypasses in patients with critical limb ischemia. J Vasc Surg. 2015;62:974-983. 
42. Papakonstantinou NA, Baikoussis NG, Goudevenos J, et al. No touch technique of saphenous vein harvesting: Is great graft patency rate provided? J Thorac Cardiovasc Surg. 2015;150:880-888.

43. Enrici E. Insuficiencia Venosa cronica de miembros inferiores. Ed Celcius. 1992;9:152-153.
44. Onoratti D. Diminution of distal venous pressure in deep venous insufficiency syndrome by reduction of the longitudinal caliber of the femoral vein. Phebologie. 1997;125-130.

45. Simkin R. Tratado de patología veonsa y linfática . Ed Medrano. 2008;27:550-552. 